\title{
Chronic disease self-management support for persons with dementia, in a clinical setting
}

This article was published in the following Dove Press journal:

Journal of Multidisciplinary Healthcare

25 January 2017

Number of times this article has been viewed

\author{
Joseph Elias Ibrahim' \\ Laura J Anderson' \\ Aleece MacPhail ${ }^{2}$ \\ Janaka Jonathan Lovell ${ }^{2}$ \\ Marie-Claire Davis' \\ Margaret Winbolt ${ }^{3}$ \\ 'Department of Forensic Medicine, \\ Monash University, Southbank, \\ ${ }^{2}$ Ballarat Health Services, Ballarat, \\ ${ }^{3}$ Australian Centre for Evidence Based \\ Aged Care, College of Science, Health \\ and Engineering, La Trobe University, \\ Melbourne, VIC, Australia
}

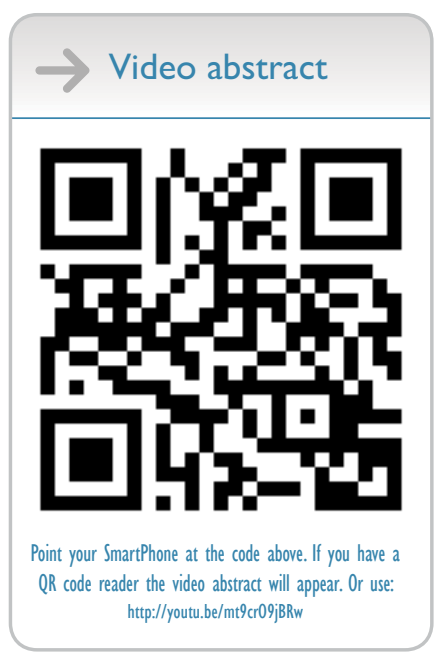

Correspondence: Joseph Elias Ibrahim Department of Forensic Medicine, Monash University, 65 Kavanagh Street, Southbank, VIC 3006, Australia

Tel +6I 399030555

Fax +6I 396827353

Email joseph.ibrahim@monash.edu
Abstract: The burden of chronic disease is greater in individuals with dementia, a patient group that is growing as the population is aging. The cornerstone of optimal management of chronic disease requires effective patient self-management. However, this is particularly challenging in older persons with a comorbid diagnosis of dementia. The impact of dementia on a person's ability to self-manage his/her chronic disease (eg, diabetes mellitus or heart failure) varies according to the cognitive domain(s) affected, severity of impairment and complexity of self-care tasks. A framework is presented that describes how impairment in cognitive domains (attention and information processing, language, visuospatial ability and praxis, learning and memory and executive function) impacts on the five key processes of chronic disease self-management. Recognizing the presence of dementia in a patient with chronic disease may lead to better outcomes. Patients with dementia require individually tailored strategies that accommodate and adjust to the individual and the cognitive domains that are impaired, to optimize their capacity for self-management. Management strategies for clinicians to counter poor self-management due to differentially impaired cognitive domains are also detailed in the presented framework. Clinicians should work in collaboration with patients and care givers to assess a patient's current capabilities, identify potential barriers to successful self-management and make efforts to adjust the provision of information according to the patient's skill set. The increasing prevalence of age-related chronic illness along with a decline in the availability of informal caregivers calls for innovative programs to support self-management at a primary care level.

Keywords: chronic disease, dementia, self-management, cognitive domains

\section{Background}

Chronic disease is the leading cause of ill-health in developed nations and causes two-thirds of all deaths worldwide. ${ }^{1}$ The burden of chronic disease is greater in people with dementia, ${ }^{2,3}$ and this population is growing with an aging population. By 2050 , the global population of those aged $\geq 80$ years is projected to reach 379 million ${ }^{4}$ and there will also be 115.4 million people with dementia. ${ }^{5}$ Contemporary dementia care requires a positive and enabling approach that supports the person to live well and remain as involved in their care as is possible within the limitations of impaired cognitive domains.

Appropriate care and management may prevent or delay chronic disease and reduce progression and disability. ${ }^{6,7}$ Successful chronic disease intervention involves a coordinated multidisciplinary care team, with a central core of patient self-management. ${ }^{7,8}$ However, strategies to develop effective self-management, especially in persons with 
dementia, appear to be lacking. There remain high rates of nonadherence to both medication and prescribed lifestyle change among patients with chronic diseases, with considerable associated economic and health burden as a result. ${ }^{9-12}$

Lorig and Holman ${ }^{13}$ have characterized self-management into five core processes (Table 1) that each requires a complex set of physical, emotional and cognitive abilities. ${ }^{14,15}$ Conceptualizations of self-management tend to be based on self-efficacy or social cognitive theory. ${ }^{12,13}$ From a cognitive perspective, self-management involves a dynamic and continuous process of self-regulation and adaptation to feedback.

Therefore, decrements in cognitive functioning, level of insight into own abilities, previous coping mechanisms and the social context impede an individual's ability to successfully self-manage chronic disease unless treatment and support approaches are adapted accordingly. ${ }^{16}$ However, the current health care system relies on the assumption that older populations have well-developed skills required for selfmanagement of chronic disease. A person's ability to selfmanage is also prone to be overestimated as dementia often goes undiagnosed (Table 2) until significant deterioration has developed. ${ }^{17}$ Clinicians must acknowledge that in addition to the relationship between cognition and self-management, this ability is also modulated by a range of complex, dynamic and interlinked factors, including age, race, socioeconomic status, participation in self-management education programs, education level, doctor-patient interaction, disease knowledge, disease severity, experience with disease, social support and psychosocial well-being. ${ }^{18-20}$

Multiple models that describe the cognitive domains required for general day-to-day adaptive functioning exist. ${ }^{12}$ Commonly described domains include attentional functions, speed of information processing, visuospatial and constructional skills, new learning and memory, receptive and expressive language, praxis, abstract reasoning and executive functions (which include self-monitoring, problem identification, planning, judgment, insight and response regulation). ${ }^{21}$ The impact of dementia on a patient's ability to self-manage will vary according to the cognitive domain(s) affected, severity of the impairment and complexity of the self-care tasks.

A better understanding of how different forms of cognitive impairment may impact on the key skills of selfmanagement will better enable clinicians' identification and response to the causes of treatment non-adherence.

\section{Aim}

We describe the challenges that older patients with a comorbid dementia syndrome and clinicians may face in chronic disease management and the potential interventions aimed at improving self-management. A framework is presented for the purpose of identifying the impact of specific cognitive domains on self-management processes as well as the measures clinicians may take to address these and hence improve management of these persons.

\section{Describing the effect of dementia syndromes on the domains of chronic disease self-management}

Lorig and Holman ${ }^{13}$ described the five key processes of disease self-management as problem identification and solution generation, decision-making, utilizing appropriate resources, working with clinicians and "taking action". Impairment of specific cognitive domains may impact each process differently (Table 1). For instance, mild cognitive impairment and Alzheimer's disease predominantly impact learning and memory, frontotemporal dementia impacts language and executive function, while vascular dementia impacts domains of attention, information processing as well as visuospatial ability and praxis. ${ }^{22}$ Dementia syndromes also vary in their profile of impairment across cognitive domains; thus, clinicians must be able to acknowledge that patients require individually tailored strategies to optimize their capacity for self-management (Table 1).

\section{Process I: identifying problems and generating realistic solutions}

Process 1 is identifying problems and generating realistic solutions. This is a cognitively demanding process and likely to be overwhelming for an individual with declining cognitive capabilities. Patients with poor executive functions may be confused or overly agitated and combative as it is difficult for them to shift their thinking or consider alternate options presented to them. Conversely, these patients may appear passive and submissive to all recommendations that a clinician suggests, as they are unable to generate ideas or solve problems independently (Table 1). ${ }^{23,24}$ Patients with mild-to-moderate dementia may have some awareness of their declining health and/or cognitive functioning, but they may be reluctant to acknowledge this for fear that it will result in a loss of their independence. This scenario makes it difficult for the clinician to be certain that patients have a sound understanding of their condition and its implications. ${ }^{25}$ Many forms of dementia are characterized by "rapid forgetting", which means that even patients who have attended to important information during a visit are likely to have forgotten it by the time they return home (Table 1). ${ }^{26,27}$ 


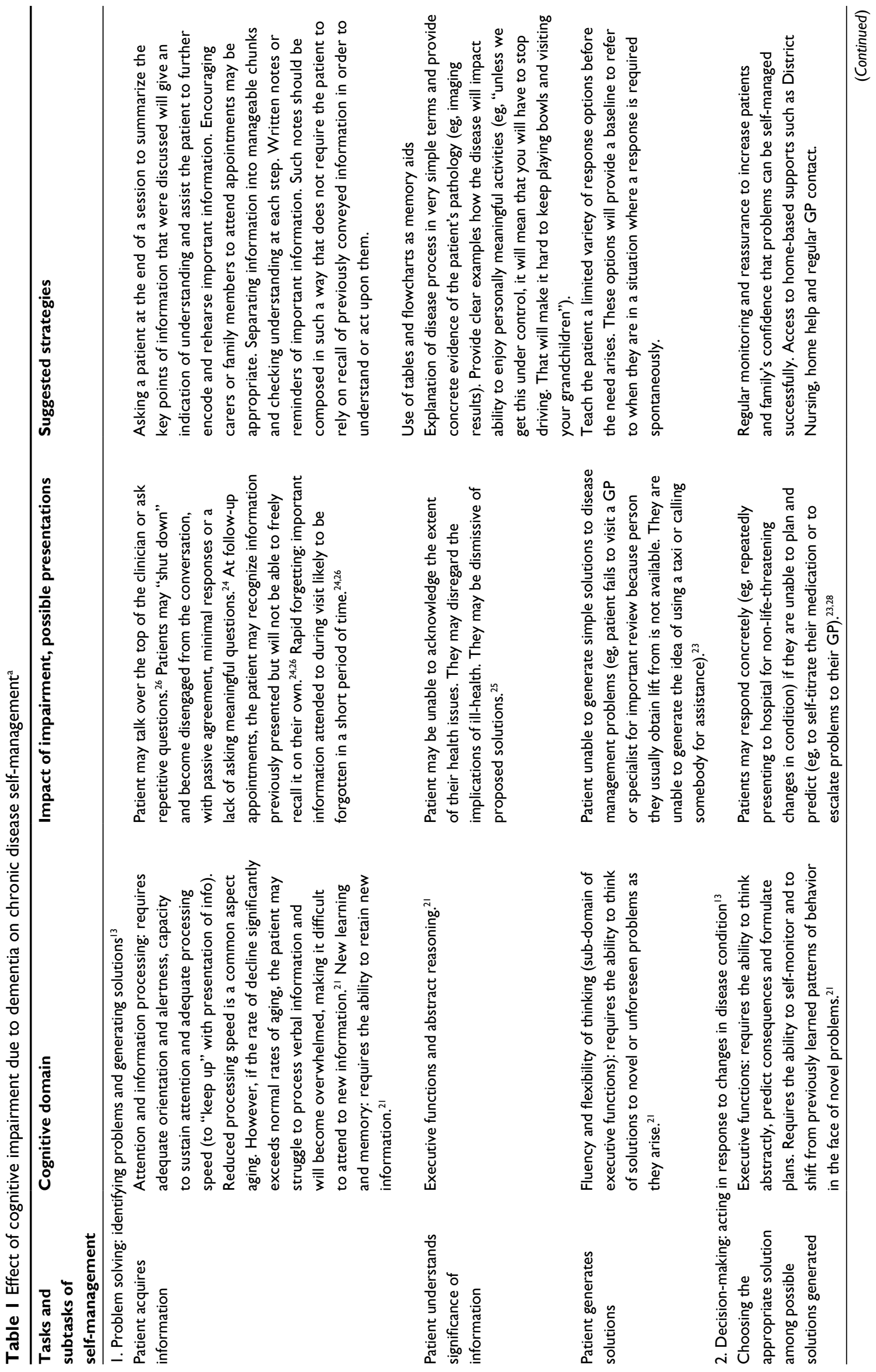




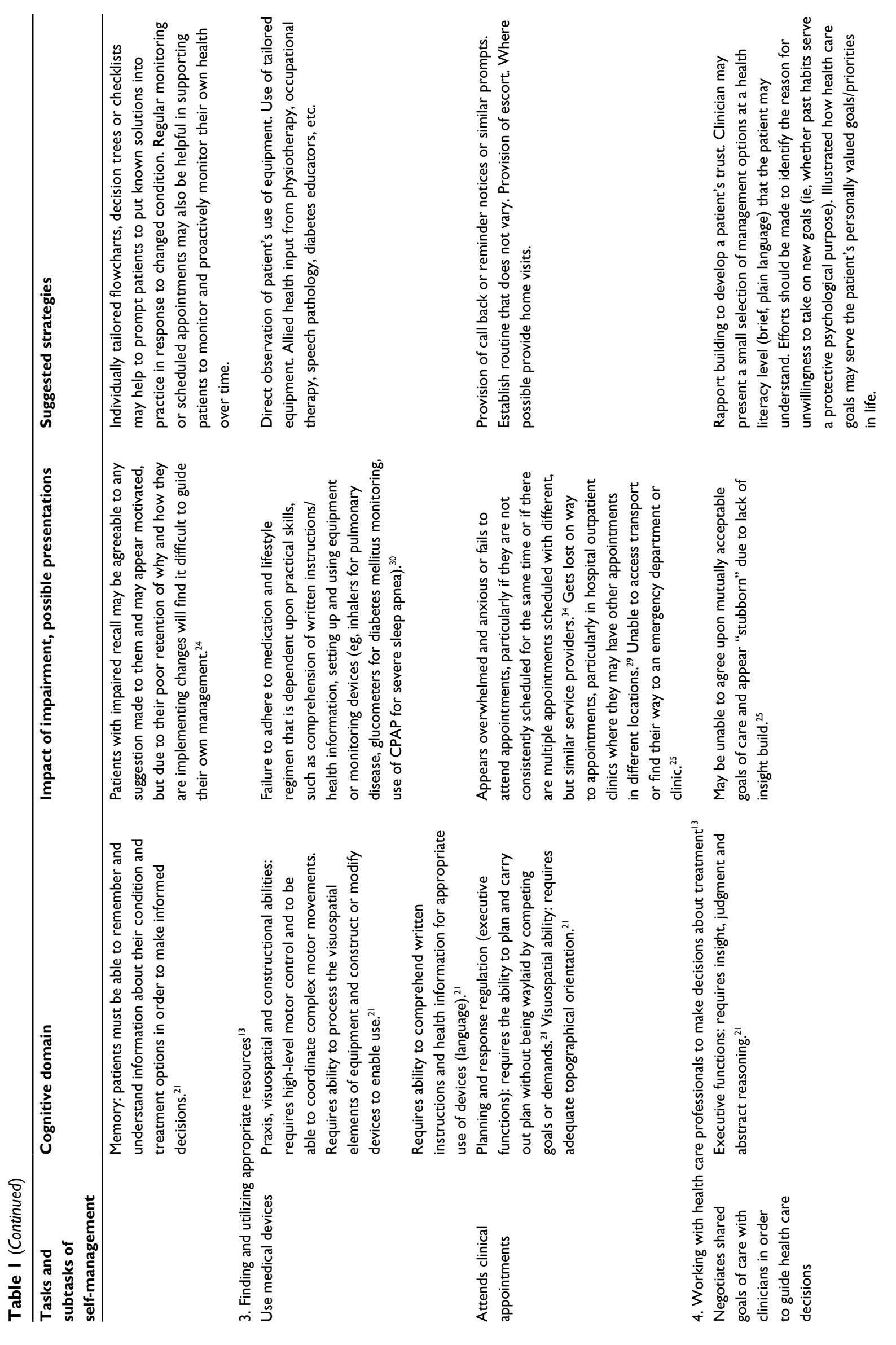



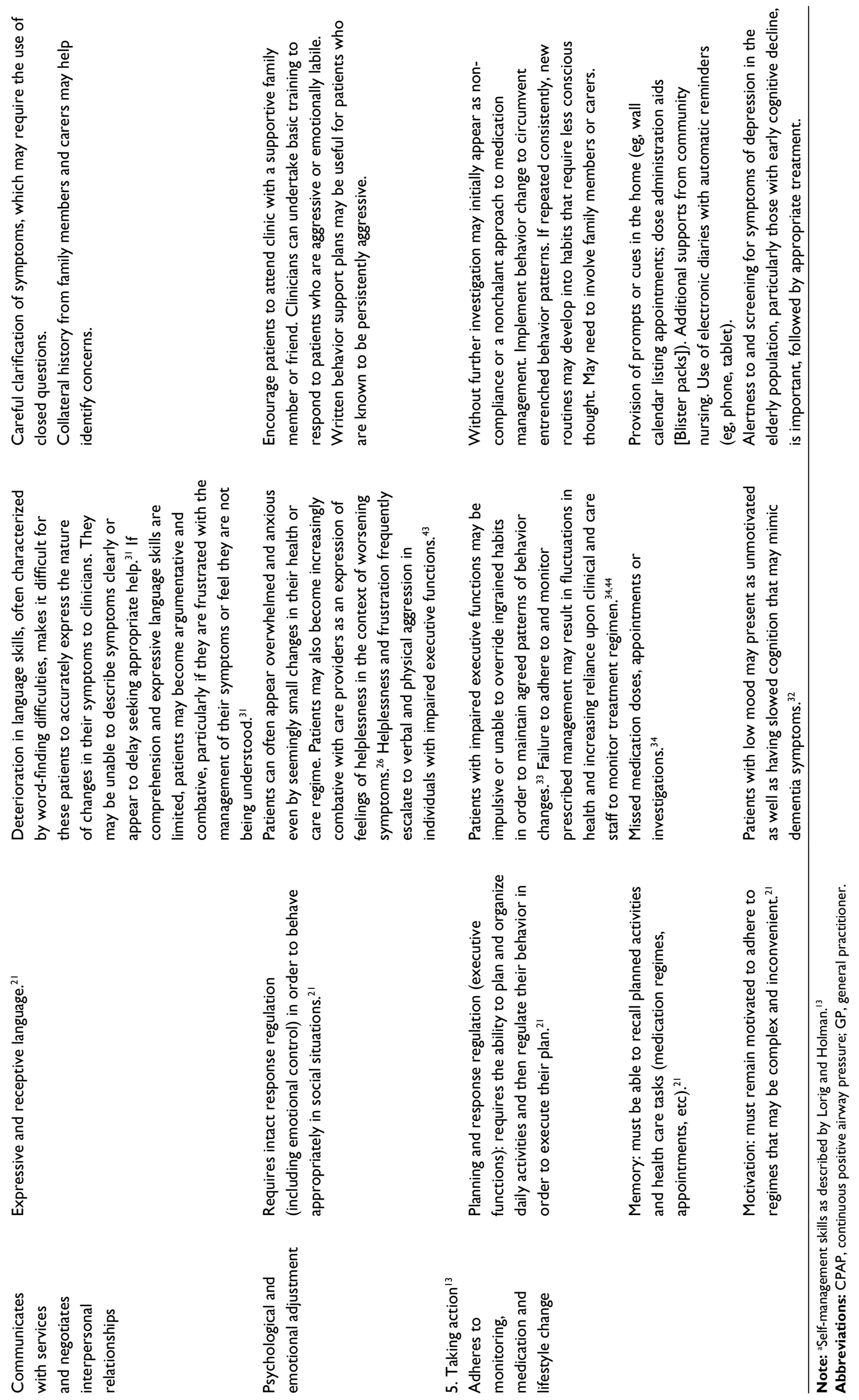
Table 2 Reasons for under-recognition of dementia and chronic disease

\begin{tabular}{|c|c|}
\hline Reason & Issues related to under-recognition \\
\hline $\begin{array}{l}\text { Health system is under-prepared for } \\
\text { a relatively new area of medicine }\end{array}$ & $\begin{array}{l}\text { Rapid surge in prevalence of dementia in recent decades. }{ }^{5} \text { Dementia only recognized by the Australian } \\
\text { government as a National Health Priority Initiative (Australian Institute of Health and Welfare) in } 2005 .^{45} \\
\text { Chronic disease management and self-management models are a relatively new field. }{ }^{23}\end{array}$ \\
\hline Subtle onset of disease & $\begin{array}{l}\text { Subtle difficulties in the performance of everyday activities are common in individuals with mild cognitive } \\
\text { impairment } 2 \text { years before a diagnosis of dementia. }{ }^{46}\end{array}$ \\
\hline $\begin{array}{l}\text { Health professionals lack skills to } \\
\text { recognize dementia }\end{array}$ & $\begin{array}{l}\text { Often physicians may not recognize subtle cognitive deficits during routine office visits. Increased } \\
\text { awareness is needed in the health care sector. }{ }^{17} \text { Rate and functional impact of cognitive decline differ } \\
\text { across patients. Therefore, establishing what is normal age-related decline as opposed to severe decline } \\
\text { for a patient might be difficult. }{ }^{47} \text { Patients/carers may not recognize early symptoms of cognitive decline as } \\
\text { a pertinent health issue and/or may choose not to report these to their general practitioner. }{ }^{39}\end{array}$ \\
\hline $\begin{array}{l}\text { Limited awareness of issue by health } \\
\text { professionals }\end{array}$ & $\begin{array}{l}\text { Increasing sub-specialization leads to clinicians focusing on single organs or systems, leading to reduced } \\
\text { awareness of the patient's overall functioning, including signs of cognitive impairment. }{ }^{17,39} \text { Health } \\
\text { professional awareness of dementia may be limited. }{ }^{17,39}\end{array}$ \\
\hline Fear and social stigma of disease & $\begin{array}{l}\text { Ongoing social stigma of dementia is also present among clinicians. }{ }^{17,39} \text { Patients may be fearful of a loss } \\
\text { of independence, which may hinder patient willingness to disclose symptoms/abilities to the general } \\
\text { practitioner. }{ }^{39}\end{array}$ \\
\hline Assumptions about dementia & $\begin{array}{l}\text { Belief that dementia will present as severe and obvious impairment. }{ }^{5} \text { Belief that the need to manage } \\
\text { chronic disease is not relevant in persons with dementia as the perception of the overall prognosis } \\
\text { is poor. Attitude that the relative absence of therapy for dementia is justification for not making a } \\
\text { diagnosis. }{ }^{47} \text { Belief that the carer is able to manage all health-related issues. }\end{array}$ \\
\hline Social isolation & $\begin{array}{l}\text { Patients without family or carers can hinder diagnosis as some screening tools (eg, functional assessments) } \\
\text { rely on caregiver observation and report. }{ }^{48} \text { The patient with dementia may lack insight and be too } \\
\text { cognitively impaired to provide an accurate history or attend a medical appointment independently. }{ }^{39}\end{array}$ \\
\hline
\end{tabular}

An example of a skill required for this process is an understanding of the significance of important information. If individuals with dementia or cognitive impairment have deficits in the domain of executive function, they may not be able to acknowledge conceptually the extent of their health issues. Additionally, they may be dismissive of proposed solutions as it is difficult to comprehend alternate options to what their current course of management may be. ${ }^{21,25}$ Clinicians may circumvent these short comings by explaining the disease in simple terms and providing solid evidence of the patients' pathology (eg, imaging results) as well as discussing how the disease will impact their ability to enjoy meaningful activities (Table 1).

\section{Process 2: decision-making - acting in response to changes in disease condition}

Process 2 of self-management of chronic diseases requires decision-making by the patients on a daily basis to respond to changes in their condition and the environment. This requires the ability to think abstractly, conceptualize plans and predict consequences. It also requires patients to have intact learning and memory systems in order to use frameworks that aid decision-making (Table 1).

Patients with impaired memory or executive functions may frequently present to the emergency department when they notice subtle, non-life-threatening changes in their health. ${ }^{23,28}$ This pattern of behavior indicates that the patients are able to monitor their health and effectively identify changes but lacks the capacity to 1) retain the information provided to them by treating staff about how to best respond to such changes in the future and/or 2) generate different ideas about how to act accordingly. ${ }^{24}$ An example of an ability required to carry out this process is to choose appropriate solutions among a variety of solutions generated by the individual (if they are able to generate solutions in the first instance [Table 1, subtask (Process 1\}]) according to changes in their condition/environment. Patients who have impairments in memory may not be able to remember or understand information about their condition and, hence, may not be able to make efficacious and informed decisions to choose the appropriate solution that addresses their situation..$^{21}$ Although these persons may be agreeable to clinician suggestions and may appear motivated, due to poor information retention, they will find it difficult to guide their own management when required. ${ }^{24}$ They may benefit from management strategies including tailored flowcharts, decision trees or checklists to prompt implementation of known solutions, in response to a changed condition. Regular monitoring or scheduled appointments may be helpful in supporting these patients to monitor and proactively monitor their health over time (Table 1). 


\section{Process 3: finding and utilizing appropriate resources}

Process 3 requires the ability to find and use appropriate resources. The treating team needs to consider whether the patient has the necessary motor skills to manage therapeutic devices (eg, medication aids, glucometers, inhalers, home oxygen). The team also needs to evaluate whether the patient has the cognitive skills to access vital health care information (eg, seeking advice via telephone services, accessing a nutrition guide for diabetes mellitus through the Internet) (Table 1). Process 3 also requires the ability to process the visuospatial elements of equipment and construct or modify devices to enable their use, as well as remembering how visuospatial mechanisms work (eg, which way to turn the dial on their insulin pen to increase or decrease their dose) (Table 1).

Patients with dementia often experience symptoms of apraxia in the early stages and may have difficulty with these tasks and therefore appear clumsy. If the impairment is one of higher level praxis (ideational or conceptual praxis), the patients may be unable to perform action sequences in the appropriate order, even for well-learned procedures that they can explain verbally (eg, a patient starts blood pressure monitoring before placing cuff over arm) (Table 1).

Progressive impairment of language function in dementia (eg, primary progressive aphasia) may eventually result in dyslexia, which will impact a patient's comprehension of written instructions and important health information (Table 1).

Additionally, patients with executive function deficits may have impairments in planning and response regulation that may hinder their ability to find their way to appointments or access the necessary transport to the clinic. ${ }^{25,29}$

As mentioned previously, a skill required for this process is the appropriate use of medical devices necessary for chronic disease management (eg, inhalers in COPD, glucometers in diabetes, continuous positive airway pressure equipment in sleep apnea, etc). Praxis, visuospatial and constructional domains confer motor control, the ability to coordinate complex motor movements and processing of the visuospatial elements of equipment to construct/modify devices to enable their use. ${ }^{21}$ Patients with impairment in these domains may fail to adhere to medication and lifestyle regimen that is dependent on practical skills such as comprehension of written instructions/health information, setting up and using equipment or monitoring devices. ${ }^{30}$ Potential solutions may include direct observation of the patient's use of equipment, use of tailored equipment and allied health input by physiotherapy, occupational therapy and speech pathology to allow better use of these devices tailored to patient capabilities (Table 1).

\section{Process 4: work with health care providers to make informed choices about their treatment}

Process 4 requires achieving agreement on overarching goals of care, as well as negotiating specific treatment strategies with health care providers. This relies on the ability for abstract thought, insight and planning (executive functions), as well as adequate communication skills to work collaboratively (Table 1). Impaired executive functions may be evidenced by a patient's resistance to implementing lifestyle or treatment changes recommended by clinicians and appearing unwilling to consider suggested options, due to a lack of insight into disease progression. ${ }^{25}$ Deterioration in language skills, often characterized by word-finding difficulties, is common in cognitive decline, and as such it may be difficult for these patients to accurately express the nature of changes in their symptoms to clinicians. ${ }^{31}$ A skill required for this process is the ability to communicate with services and negotiate interpersonal relationships. Impairments in the expressive and receptive language domains may manifest as word-finding difficulties, which results in these persons having issues with explaining the nature of their symptoms, changes in their symptoms, management preferences, circumstances and seeking help in a timely manner. ${ }^{21}$ Furthermore, limited comprehension and expressive language skills may result in patients becoming argumentative and combative especially if they are frustrated with the management of their symptoms or feel misunderstood by clinicians/allied health staff. ${ }^{31}$ Management strategies to counter this involve careful clarification of symptoms using closed questions and obtaining a collateral history from carers or family members (Table 1).

\section{Process 5: taking action}

Process 5 requires implementing agreed-upon courses of action that involves the culmination of many of the abovedescribed cognitive skills and processes and is dependent on successfully establishing the previous steps. If patients have successfully attended to and understood information, negotiated care plans and identified when to act, they must still be able to remember to take action and remain motivated and physically able to complete tasks (Table 1).

When patients have an awareness of their own physical and cognitive decline, one significant consequence is deterioration in mood and motivation. Mood issues associated with adjusting 
to the vast array of age-related changes are often an overlooked obstacle to developing good self-care. In particular, depressive symptoms often have a "dampening effect" upon cognition and may negatively impact upon motivation, concentration and memory, social engagement and personality - often mimicking the onset of dementia. ${ }^{32}$ Patients with low mood states may present as unwilling or incapable of following multistep instructions or with a lack of confidence in their ability to independently follow such steps. They may also be preoccupied and have difficulty attending to, and thus learning and retaining, important information discussed.

Patients with impaired executive functions may have difficulty applying a process designed to take over from deeply entrenched behavior patterns - eg, dietary habits developed over a lifetime (Table 1). ${ }^{33}$ An example of a skill required to fulfill this process is adherence to monitoring, medication and lifestyle. These are well-established, critical features of self-management in chronic disease that, if not complied with, may result in poor outcomes. ${ }^{9-12}$ If patients are unable to recall planned activities and health care tasks due to memory impairments, they may miss medication doses, appointments or scheduled investigations. ${ }^{21,34}$ In order to improve self-management in this subset of cognitively impaired persons, prompts or cues in the home (eg, wall calendar listing appointments, dose administration aids) or use of electronic diaries with automatic reminders may be employed. Additional supports from community nursing may be utilized to ensure adherence to recommended monitoring, medication and lifestyle, particularly for those patients who have severe memory deficits.

\section{Implications for clinicians: recognizing cognitive decline and supporting self-management}

Recognizing the presence of dementia in a person with chronic disease may lead to better patient outcomes. Optimal disease control through self-management requires a complex set of skills that may be impacted by declining physical, emotional and cognitive health.

A key step for clinicians is an understanding that nonadherence or poor disease control could, in part, be due to an unrecognized comorbid dementia (Table 2). Some deterioration of cognitive skills with age is normal and expected; it is when the level of deterioration is over and above typical rates that it can start to have a negative impact upon a patient's functional capacity, and thus potentially impede efforts to effectively implement self-management care plans.

The complex composition of different cognitive domains and how they interact is difficult to understand and assess, even for skilled clinicians. ${ }^{35}$ Additionally, the identification of mild dementia and other indicators of a neurodegenerative process in a patient with multiple comorbidities is a difficult one that can often be overlooked in favor of managing more pressing medical issues. ${ }^{8,17}$ This is particularly pertinent when considering reductions in higher order executive functions, as this level of thinking requires coordination of multiple cognitive skills. Clinicians often have limited opportunity to observe this level of thinking skills in the short space of time in which they are with their patients, unless specifically looking for and testing these skills. ${ }^{17,35}$ Formal cognitive testing is required to determine the presence or seriousness of any decline. Dementia is under-recognized with 15\%-25\% of patients aged over 75 years in general practices meeting criteria for cognitive impairment. ${ }^{36,37}$ Timely recognition of undiagnosed dementia or cognitive impairment symptoms can aid clinicians in deciding which persons would be suitable for comprehensive neuropsychological assessment and identifying those who would benefit from implementation of recommended techniques for continued self-management. The Mini-Mental State Examination is a commonly used screening tool for dementia; however, it has significant limitations and does not adequately assess executive functioning, making it an unreliable screening measure for early stages of dementia. Other brief screening tests designed to assess executive functioning also have shortcomings. ${ }^{35}$

Clinical assessment may be able to more effectively identify executive dysfunction by systematically observing and recording their patient's understanding and ability to undertake complex daily actions. ${ }^{38}$ For example, asking simple questions such as the date, time and knowledge of current world or local events can provide the clinician an insight into the patient's awareness of their environment.

Consistent errors or confusion can indicate executive dysfunction, even if the patient provides reasoning for such confusion. Similarly, patients who are highly tangential in conversation, or conversely perseverate on particular topics, may be experiencing some executive dysfunction. Clinicians should take note of how difficult it is to redirect patients in these situations; if a pattern of this behavior is established, executive dysfunction is likely.

It is not realistic or appropriate to refer all patients for a comprehensive neuropsychological assessment to determine the likelihood of dementia. ${ }^{35,39}$ Clinicians should instead focus on developing an understanding of the functional representation of these areas of cognitive functioning and assess (by means of making clinical observations and having discussions with their patients) their capability of undertaking the tasks required for self-management. 
Supportive and adaptive strategies to assist patients to integrate and consolidate new information can be employed to help compensate for cognitive decline. ${ }^{14,40}$ There is also a need for health professionals providing care for patients with chronic disease to develop a flexible and response approach to establishing care protocols to match patient needs and capabilities. Hence, we propose a framework that describes the effect of cognitive impairment on self-care processes. In this framework, we suggest how clinicians may address a patient's individual cognitive deficits to circumvent selfmanagement issues and, therefore, improve overall chronic disease management for these persons. This approach must be modified as cognitive function continues to deteriorate.

The inevitable progression and functional decline experienced by patients with dementia makes ongoing monitoring of their health and capacity for chronic disease self-management essential. It is vital to continue supporting independence and empowering patients within their capabilities. It is all too easy to strip all self-management tasks from persons with dementia and instead to rely on carers. This approach may be counterproductive, increasing dependence and caregiver stress, and is disrespectful to the patient. ${ }^{13-15}$ The increasing prevalence of age-related chronic illnesses along with a decline in the availability of informal carers increases the importance of primary care providers and a need for innovative programs to support self-management. ${ }^{41}$ Broader education and training for clinicians about dementia and key functional indicators for different types of dementia would be valuable for primary care providers and specialists who regularly manage patients with chronic disease. ${ }^{17,42}$ Another strategy is development of clinical practice guidelines and tools for tailoring management of specific chronic diseases for patients with coexisting dementia. Optimal management of common chronic diseases such as diabetes mellitus, heart failure and chronic pulmonary disease requires a different emphasis on each of the five self-management tasks.

Development of more accurate, functional and behaviorbased cognitive screening tools for use by clinicians to identify possible dementia would be helpful. Not only would these assist clinicians who are not specifically trained in neuropsychology to efficiently characterize their patient's cognitive profile, but they would also facilitate long-term care planning and assist in monitoring of cognitive functioning over time. Involvement of geriatric medicine expertise, occupational therapist support and other specialized support services (eg, aged care assessment teams) as required by the patient's needs would also be valuable in providing holistic care to this growing patient group.

\section{Conclusion}

Managing chronic diseases in the context of cognitive impairment is complex, and patients with dementia are vulnerable to poorer outcomes if they are unable to negotiate selfmanagement. Further to recognizing cognitive impairment, a holistic view encompassing personal capabilities, previous coping mechanisms and the individual's social context should be considered when formulating management strategies for this population. A greater focus needs to be placed on care services for older adults that empower consumers, support independence and improve the viability and sustainability of the health and aged care sectors.

Providing education and relevant care information to the patient is not sufficient for implementing a self-management strategy. In reality, self-management differs from patient education, in that it incorporates cognitive tasks and strategies that enable patients to change their behavior and manage their condition..$^{13}$

Prudent practice requires the clinician to take responsibility for assessing the patient's current capabilities, identify potential barriers to successful self-management and make efforts to adjust the provision of information according to the patient's skill set.

\section{Acknowledgment}

Funding for this work was provided by Internal Funds Monash University, Ballarat Health Services and Dementia Training Centres, Australia.

\section{Disclosure}

The authors report no conflicts of interest in this work.

\section{References}

1. World Health Organization. Preventing Chronic Diseases: A Vital Investment: WHO Global Report. Switzerland: WHO Press; 2005:200.

2. Schubert CC, Boustani M, Callahan CM, et al. Comorbidity profile of dementia patients in primary care: are they sicker? J Am Geriatr Soc. 2006;54(1):104-109.

3. Zekry D, Herrmann FR, Grandjean R, et al. Demented versus nondemented very old inpatients: the same comorbidities but poorer functional and nutritional status. Age Ageing. 2008;37(1):83-89.

4. United Nations Department of Economic and Social Affairs. World Population Ageing, 1950-2050. New York, NY: United Nations; 2002:44.

5. Prince M, Bryce R, Albanese E, et al. The global prevalence of dementia: a systematic review and meta analysis. Alzheimers Dement. 2013;9(1):63.e-75.e.

6. Goldman DP, Smith JP. Can patient self-management help explain the SES health gradient? Proc Natl Acad Sci USA. 2002;99(16):10929-10934.

7. Lorig KR, Sobel DS, Stewart AL, et al. Evidence suggesting that a chronic disease self-management program can improve health status while reducing hospitalization: a randomized trial. Med Care. 1999;37(1):5-14.

8. Wagner EH, Austin BT, Von Korff M. Organizing care for patients with chronic illness. Milbank Q. 1996;74(4):511-544.

9. Cramer JA. A systematic review of adherence with medications for diabetes. Diabetes Care. 2004;27(5):1218-1224. 
10. Sontakke S, Budania R, Bajait C, Jaiswal K, Pimpalkhute S. Evaluation of adherence to therapy in patients of chronic kidney disease. Indian $J$ Pharmacol. 2015;47(6):668.

11. Marti CN, Georgiopoulou VV, Giamouzis G, et al. Patient-reported selective adherence to heart failure self-care recommendations: a prospective cohort study: the Atlanta Cardiomyopathy Consortium. Congest Heart Fail. 2013;19(1):16-24.

12. Dulmen S, Sluijs E, Dijk L, et al. Patient adherence to medical treatment: a review of reviews. BMC Health Serv Res. 2007;7(1):1-13.

13. Lorig K, Holman H. Self-management education: history, definition, outcomes, and mechanisms. Ann Behav Med. 2003;26(1):1-7.

14. Swendeman D, Ingram BL, Rotheram-Borus MJ. Common elements in self-management of HIV and other chronic illnesses: an integrative framework. AIDS Care. 2009;21(10):1321-1334.

15. Cramm J, Hartgerink J, Steyerberg E, et al. Understanding older patients' self-management abilities: functional loss, self- management, and wellbeing. Qual Life Res. 2013;22(1):85-92.

16. Sudore RL, Yaffe K, Satterfield S, et al. Limited literacy and mortality in the elderly: the health, aging, and body composition study. J Gen Intern Med. 2006;21(8):806-812.

17. Chodosh J, Petitti DB, Elliott M, et al. Physician recognition of cognitive impairment: evaluating the need for improvement. J Am Geriatr Soc. 2004;52(7):1051-1059.

18. Moser DK, Watkins JF. Conceptualizing self-care in heart failure: a life course model of patient characteristics. $J$ Cardiovasc Nurs. 2008;23(3):205-218.

19. Kisokanth G, Prathapan S, Indrakumar J. Factors influencing selfmanagement of diabetes mellitus: a review article. J Diabetol. 2013;3:1.

20. Davis KK, Himmelfarb CR, Szanton SL, Hayat MJ, Allen JK. Predictors of heart failure self-care in patients who screened positive for mild cognitive impairment. J Cardiovasc Nurs. 2015;30(2):152-160.

21. American Psychiatric Association. Neurocognitive disorder. Diagnostic and Statistical Manual of Mental Disorders. 5th ed. Washington, Arlington, VA: American Psychiatric Publishing; 2013.

22. Karantzoulis S, Galvin JE. Distinguishing Alzheimer's disease from other major forms of dementia. Expert Rev Neurother. 2011;11(11):1579-1591.

23. Alzheimer's \& Dementia. 2016 Alzheimer's disease facts and figures. Alzheimers Dement. 2016;12(4):459-509.

24. Jones D, Drew P, Elsey C, et al. Conversational assessment in memory clinic encounters: interactional profiling for differentiating dementia from functional memory disorders. Aging Ment Health. 2016;20(5):500-509.

25. Pathak KP, Montgomery A. General practitioners' knowledge, practices, and obstacles in the diagnosis and management of dementia. Aging Ment Health. 2015;19(10):912-920.

26. De Vries K. Communicating with older people with dementia. Nurs Older People. 2013;25(4):30-37.

27. Reed BR, Paller KA, Mungas D. Impaired acquisition and rapid forgetting of patterned visual stimuli in Alzheimer's disease. J Clin Exp Neuropsychol. 1998;20(5):738-749.

28. Passini R, Rainville C, Marchand N, Joanette Y. Way finding in dementia of the Alzheimer type: planning abilities. J Clin Exp Neuropsychol. 1995; 17(6):820-832.
29. Yew B, Alladi S, Shailaja M. Lost and forgotten? Orientation versus memory in Alzheimer's disease and frontotemporal dementia. J Alzheimer Dis. 2013;33:473-481.

30. Allen SC. Competence thresholds for the use of inhalers in people with dementia. Age Ageing. 1997;26(2):83-86.

31. Voyer P. Communicating with people with dementia: avoiding mistakes. Can Nurse. 2015;111(5):10.

32. Gutzmann H, Qazi A. Depression associated with dementia. Gerontol Geriat. 2015;48:305.

33. Bidzan L, Bidzan M, Pachalska M. Aggressive and impulsive behavior in Alzheimer's disease and progression of dementia. Med Sci Monit. 2012;18(3):CR182-CR189.

34. Cheon SM, Park KW, Kim JW. Identification of daily activity impairments in the diagnosis of Parkinson disease dementia. Cogn Behav Neurol. 2015;28(4):220-228.

35. Ismail Z, Rajji TK, Shulman KI. Brief cognitive screening instruments: an update. Int J Geriatr Psychiatry. 2010;25(2):111-120.

36. Luck T, Riedel-Heller SG, Kaduszkiewicz H, et al; AgeCoDe Group. Mild cognitive impairment in general practice: age-specific prevalence and correlate results from the German study on ageing, cognition and dementia in primary care patients (AgeCoDe). Dement Geriatr Cogn Disord. 2007;24(4):307-316.

37. Rait G, Fletcher A, Smeeth L, et al. Prevalence of cognitive impairment: results from the MRC trial of assessment and management of older people in the community. Age Ageing. 2005;34(3):242-248.

38. Kipps CM, Hodges JR. Cognitive assessment for clinicians. J Neurol Neurosurg Psychiatry. 2005;76(suppl 1):i22-i30.

39. Phillips J, Pond D, Goode SM; Alzheimer's Australia. Diagnosis of Dementia: Can We Do Better? Callaghan, NSW: Discipline of General Practice UoN; 2011:23.

40. Schulman-Green D, Jaser S, Martin F, et al. Processes of self-management in chronic illness. J Nurs Scholarsh. 2012;44(2):136-144.

41. Deloitte Touche Tohmatsu Limited. Deloitte Access Economics: The Economic Value of Informal Care in Australia in 2015. Deakin, ACT: Carers Australia; 2015:43.

42. Buntinx F, De Lepeleire J, Paquay L, Iliffe S, Schoenmakers B. Diagnosing dementia: no easy job. BMC Fam Pract. 2011;12(60):1-4.

43. Cipriani G, Lucetti C, Danti S. Violent and criminal manifestations in dementia. Geriatr Gerontol Int. 2016;16(5):541-549.

44. Arlt S, Lindner R, Rosler A. Adherence to medications in patients with dementia: predictors and strategies for improvement. Drugs Aging. 2008;25(12):1033-1047.

45. Australian Government: Department of Health. Portfolio Budget Statements 2005-2006: Health and Ageing Portfolio. Canberra, ACT: Department of Health; 2005. [Report. No.:1.11].

46. Gauthier S, Reisberg B, Zaudig M, et al. Mild cognitive impairment. Lancet. 2006;367(9518):1262-1270.

47. Koch T, Iliffe S; EVIDEM-ED Project. Rapid appraisal of barriers to the diagnosis and management of patients with dementia in primary care: a systematic review. BMC Fam Pract. 2010;11(52):1-8.

48. Thibault JM, Steiner RW. Efficient identification of adults with depression and dementia. Am Fam Physician. 2004;70(6):1101-1110.
Journal of Multidisciplinary Healthcare

\section{Publish your work in this journal}

The Journal of Multidisciplinary Healthcare is an international, peerreviewed open-access journal that aims to represent and publish research in healthcare areas delivered by practitioners of different disciplines. This includes studies and reviews conducted by multidisciplinary teams as well as research which evaluates the results or conduct of such teams or health

\section{Dovepress}

care processes in general. The journal covers a very wide range of areas and welcomes submissions from practitioners at all levels, from all over the world. The manuscript management system is completely online and includes a very quick and fair peer-review system. Visit http://www.dovepress.com/ testimonials.php to read real quotes from published authors. 